\title{
NOTES
}

\section{Occurrence of the Acanthocephalan Leptorhynchoides thecatus in Slimy Sculpins- A New Host Record ${ }^{1}$}

\author{
George R. Heufelder and \\ Philip J. Schneeberger \\ Great Lakes Research Division \\ University of Michigan \\ Institute of Science and Technology \\ Ann Arbor, Michigan 48109
}

\begin{abstract}
A new host (Cottus cognatus) for adults of the acanthocephalan Leptorhynchoides thecatus (Linton) is reported. Of 176 slimy sculpins examined from eastern Lake Michigan, $93 \%$ were infected by $L$. thecatus. The number of $L$. thecatus infecting slimy sculpins was directly related to size of fish. Mean number of $L$. thecatus per fish was 17 for males, 10 for females, and 3 for immatures. One male was infected with $132 \mathrm{~L}$. thecatus.
\end{abstract}

The life history of Leptorhynchoides thecatus (Linton 1891) was studied in considerable detail by DeGiusti (1949). A summary of literature concerning this species (Hoffman 1967) indicates that it inhabits the digestive tracts of many North American fish species. The intermediate host of $L$. thecatus is an amphipod (Hoffman 1967), and very commonly Hyalella azteca (Van Cleave 1920; DeGiusti 1949). Leptorhynchoides thecatus has not been previously reported to infect the slimy sculpin (Cottus cognatus).

\section{Methods}

Slimy sculpins (176 specimens) examined in this study were caught in $3-15$-m deep trawl hauls from eastern Lake Michigan in the vicinity of the J. H. Campbell Power Plant, Port Sheldon, Michigan, from April to December 1978.

Fish were frozen immediately after collection. In the laboratory, thawed specimens were preserved in $20 \%$ formalin. All L. thecatus observed in both the stomach and the intestine of

\footnotetext{
${ }^{1}$ Contribution Number 256, Great Lakes Research Division, University of Michigan.
}

sculpins were removed and counted. Parasites used for identification were taken live from slimy sculpins and placed in distilled water until the acanthocephalan's trunk was extended and the parasite was dead. The parasites were then fixed in alcohol-formalin-acetic acid solution and stained with Mayer's Paracarmine.

The nonparametric Kruskal-Wallis statistical test was used to test differences between mean densities of $L$. thecatus present in male, female, and immature slimy sculpins (Conover 1971). Although mean density of $L$. thecatus in slimy sculpins and total length of fish were correlated, the frequency distribution was nonnormal. Natural log transformation, however, produced a linear relationship between total length and density of $L$. thecatus.

\section{Results and Discussion}

Adult L. thecatus infected $93 \%$ of the slimy sculpins examined. More than half of the variation (coefficient of determination $=0.62$ ) in the total number of adult $L$. thecatus infecting slimy sculpins could be explained by length of fish (Fig. 1), with larger fish exhibiting higher mean densities than smaller ones. One fish had $132 \mathrm{~L}$. thecatus, though most had fewer than 16 worms each (Table 1). Some studies indicated that $L$. thecatus inhabit the ceca of their host (Esch et al. 1976; Vernard and Warfel 1953). However, we found no adult $L$. thecatus in the ceca of slimy sculpins, perhaps because of the small number (2-4) and size of ceca in this species. Twenty-four of the 176 sculpins examined had $L$. thecatus in the stomach; whereas, 166 had parasites in the intestine. Those parasites found in the stomach were not attached and may have been regurgitated at time of host capture. The higher mean density of adult $L$. thecatus in male compared with female slimy sculpins (Table 1) was significant at the $\alpha=0.1$ level. It is not known why females had lower infection rates than males, but most females examined had very well developed ovaries which displaced internal organs and flattened the lumen of the intestine. This may have inhibited intestinal attachment by $L$. thecatus. Although no seasonal studies on food eaten by this species in Lake Michigan were found, it is also possible that male and female slimy sculpin 


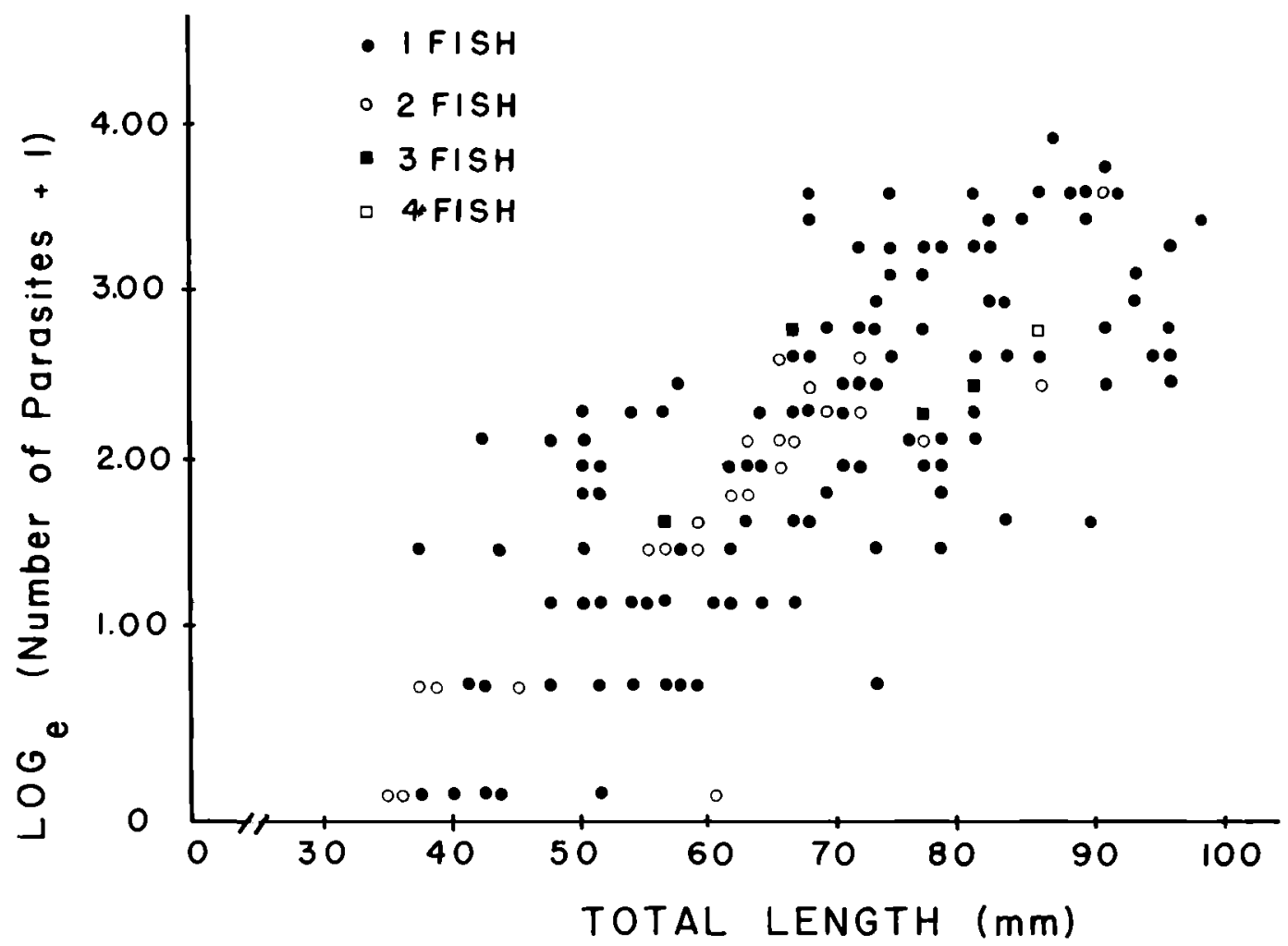

FIgURE 1.-Log-transformed ( $\mathrm{N}+1$ ) regression of numbers $(\mathrm{N})$ of Leptorhynchoides thecatus present in slimy sculpins on total length of fish.

feed on different organisms during the time of the year when recruitment of parasites is highest, and thus were differentially subject to infection.

Because fish moved into deeper, offshore water, slimy sculpins were not collected in sufficient numbers after May to allow seasonal periodicity in occurrence of adult $L$. thecatus to be examined. Esch et al. (1976) suggested that there may be seasonal trends in recruitment of adult parasites. The reported intermediate hosts for this parasite are not commonly found in the area where the sculpins used in this study were collected (Jude et al. 1978). This suggests the strong possibility that Pontoporeia hoyi, the most abundant amphipod in the area, may be serving as an intermediate host for $L$. thecatus.

\section{Acknowledgments}

This study was supported in part by the Environmental Services Department of Consumers Power Company, Jackson, Michigan. We thank Harvey Blankespoor of Hope Col-
TABLE 1.-Loadings of Leptorhynchoides thecatus in slimy sculpins from eastern Lake Michigan.

\begin{tabular}{ccccc} 
& Male & Female & $\begin{array}{c}\text { Imma- } \\
\text { ture }\end{array}$ & $\begin{array}{c}\text { All } \\
\text { fish }\end{array}$ \\
Loading & fish & fish & fish & combined \\
feature & $N=60$ & $N=82$ & $N=34$ & $N=176$ \\
\hline & Number of fish per loading
\end{tabular}

Parasites

per fish

$\begin{array}{crrrr}0 & 1 & 1 & 10 & 12 \\ 1-5 & 9 & 27 & 16 & 52 \\ 6-10 & 16 & 27 & 7 & 50 \\ 11-15 & 14 & 11 & 1 & 26 \\ 16-20 & 2 & 7 & 0 & 9 \\ 21-25 & 6 & 2 & 0 & 8 \\ 26-30 & 3 & 3 & 0 & 6 \\ 31-35 & 4 & 4 & 0 & 8 \\ 36-40 & 2 & 0 & 0 & 2 \\ 41-45 & 1 & 0 & 0 & 1 \\ 46-50 & 1 & 0 & 0 & 1 \\ >50 & 1 & 0 & 0 & 1\end{array}$

Mean loading and \% infected

Mean parasites $\begin{array}{lllll}\text { per fish } & 17 & 10 & 3 & 11\end{array}$

Percent of

\begin{tabular}{lllll} 
fish infected & 98 & 99 & 71 & 93 \\
\hline
\end{tabular}


lege, Michigan and Glenn Hoffman of the Fish Farming Experimental Station, United States Fish and Wildlife Service, Stuttgart, Arkansas for identifying the parasites. David J. Jude, Great Lakes Research Division, University of Michigan, Ann Arbor, critically reviewed the manuscript.

\section{References}

Conover, N. J. 1971. Practical non-parametric statistics. John Wiley and Sons, New York, New York, USA.

DeGuUsti, D. L. 1949. The life cycle of Leptorhynchoides thecatus (Linton), an acanthocephalan of fish. Journal of Parasitology 35:437-460.

Esch, G. W., G. C. Campbell, R. E. Connors, and J. R. Coggrns. 1976. Recruitment of helminth parasites by bluegills (Lepomis macrochirus) using a modified live-box technique. Transactions of the American Fisheries Society 105:486-490.

Hoffman, G. L. 1967. Parasites of North American freshwater fishes. University of California Press, Los Angeles, California, USA.

Jude, D. J., B. A. Bachen, G. R. Heufelder, H. T. Tin, M. H. Winnell, F. J. Tesar, and J. A. Dorr, III. 1978. Adult and juvenile fish, ichthyoplankton and benthos populations in the vicinity of the J. H. Campbell Power Plant, eastern Lake Michigan, 1977. Special Report 65, Great Lakes Research Division, University of Michigan, Ann Arbor, Michigan, USA.

Van Cleave, H. J. 1920. Notes on the life cycle of two species of Acanthocephala from freshwater fishes. Journal of Parasitology 6:167-172.

Vernard, C. E., and J. H. Warfel. 1953. Some effects of two species of acanthocephala on the alimentary canal of the largemouth bass. Journal of Parasitology 39:187-190. 